\title{
Effects of age and gender on peripheral lymphocyte micronucleus
}

Ladeira, C. 1,2 ; Viegas, S. 1,2; Gomes, M.C. ${ }^{3}$; Brito, M.1

1 Higher School of Health Technologies ; 2 CIESP - Center of Research and Studies in Public Health of Nwe University of Lisbon; 3 Faculty of Sciences of University of Lisbon

\section{Introduction}

Aging in humans appears to be associated with genetic instability. The cytokinesis-blocked micronucleus assay (CBMN) is a comprehensive method for measuring chromosome breakage, DNA misrepair, chromosome loss, non-disjunction, necrosis, apoptosis and cytostasis. Age and gender are the most important demographic variables affecting the micronucleus (MN) index and studies report frequencies in females being greater than those in males by a factor of 1.2 to 1.6 depending on the age group. It has been shown that a higher MN frequency directly corresponds to a decreased efficiency of DNA repair and increased genome instability.

\section{Aim of the Study}

Investigate an association between age and gender and the synergistic effect of both upon MN in peripheral lymphocytes in a sample of individual without any occupational exposure.

\section{Results}

The sample was constituted by 54 women and 31 men, with age mean of $32.42 \pm 8.1$ years old. Concerning to the analysis of gender, females have higher mean of $M N$ in lymphocytes (0.81 0.229) than males (0.71 0.255) - Table 1.

Table 1 - Descriptive statistics by gender of MN in lymphocytes means (mea
standard error, range)
\begin{tabular}{|c|c|c|}
\hline Gender & N & $\begin{array}{c}\text { Mean MN } \\
\text { lymphocytes } \pm \\
\text { S.E. } \\
\text { (range) }\end{array}$ \\
\hline Females & 54 & $\begin{array}{c}0.81 \pm 0.229 \\
(0-7)\end{array}$ \\
\hline Males & 31 & $\begin{array}{c}0.71 \pm 0.255 \\
(0-6)\end{array}$ \\
\hline
\end{tabular}

p>0.05 Mann-Whitney test

\section{Methodology}

The study was carried out in Portugal in a sample of 85 subjects without any occupational exposition. The evaluation of genotoxic effects was conducted by applying CBMN in peripheral blood lymphocytes. Heparinized whole-blood samples were obtained, with informed consent, from unrelated individuals, men and women, stratified according to their age: 20-30, 31-40 and 41-55 years old. Lymphocytes were isolated using Ficoll-Paque gradient and placed in RPMI 1640 culture medium with L-glutamine and red phenol added with $10 \%$ inactivated fetal calf serum, $50 \mathrm{ug} / \mathrm{ml}$ streptomycin $+50 \mathrm{U} / \mathrm{mL}$ penicillin, and $10 \mathrm{ug} / \mathrm{mL}$ phytohaemagglutinin. Duplicate cultures from each subject were incubated at $37^{\circ} \mathrm{C}$ in a humidified 5\% CO2 incubator for 44h, and cytochalasin-b 6 $\mathrm{ug} / \mathrm{mL}$ was added to the cultures in order to prevent cytokinesis. After a $28 \mathrm{~h}$ incubation, cells were spun onto microscope slides using a cytocentrifuge. Smears were air-dried and double stained with May-Grünwald-Giemsa and mounted with Entellan. The frequencies of binucleated cells with MN were determined analyzing 1000 lymphocytes from 2 slides for each subject.

The analysis of age showed that there was no consistent trend regarding the variation of MN with age - Table 2.
Table 2 - Descriptive statistics by age categories of MN in lymphocytes means (mean mean standard error, range)

\begin{tabular}{|c|c|c|}
\hline Age & N & $\begin{array}{c}\text { Mean MN lymphocytes } \\
\pm \text { S.E. } \\
\text { (range) }\end{array}$ \\
\hline $20-30$ & 36 & $\begin{array}{c}0.47 \pm 0.157 \\
(0-3)\end{array}$ \\
\hline $31-40$ & 35 & $\begin{array}{c}1.14 \pm 0.326 \\
(0-7)\end{array}$ \\
\hline$>41$ & 14 & $\begin{array}{c}0.86 \pm 0.501 \\
(0-6)\end{array}$ \\
\hline
\end{tabular}

The analysis of an association between gender, age as single variables and frequencies of MN by binary logistic regression was not statistical significant ( $p>0.05$ ). The interaction between age and gender in determining the frequencies of MN in lymphocytes was investigated and found to be not significant (Kruskal-Wallis, $p>0.05$ ).

\section{References}

A. Wojda, E. Zietkiewicz, M. Witt, Effects of age and gender on micronucleus and chromosome nondisjunction frequencies in centenarians and younger subjects, Mutagenesis Advance Access (2007) $1-6$. N. Holland, C. Bolognesi, M. Kirsch-Volders, S. Bonassi, E. Zeiger, S. Knasmuelle,
$M$. Fenech, The micronucleus assay in human buccal cells as a tool for biomonitoring DNA damage: The HuMN project perspective on curren

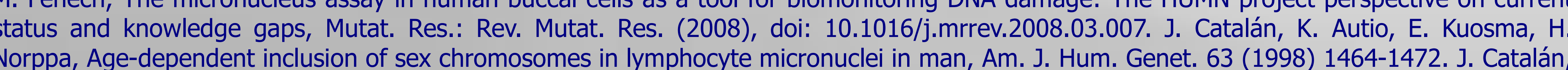
Norppa, Age-dependent inclusion of sex chromosomes in lymphocyte micronuclei in man, Am. J. Hum. Genet. 63 (1998) 1464-1472. J. Catalán,

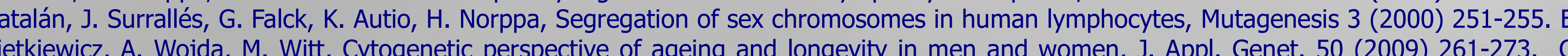
. in peripheral blood lymphocytes, Age and Ageing 28 (1999) 393-397. M. Fenech, Cytokinesis-block micronucleus cytome assay, Nature

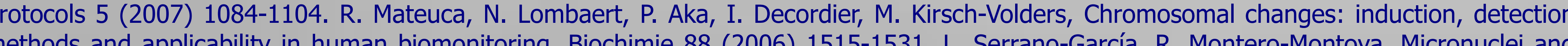

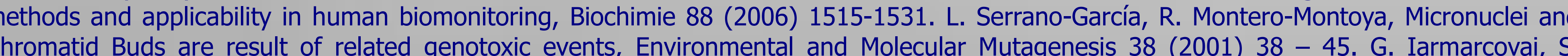
Bonassi, A. Botta, R.A. Bann, T. Orsière, Genetic polymorphisms and micronucleus formation: A review of the literature, Mutat. Res. 658 (2008) 215 - 233. M. Fenech, N. Holland, W. Chang, E. Zeiger, S. Bonassi, The Human MicroNucleus Project - An international collaborative study on the use of the micronucleus technique for measuring DNA damage in humans, Mutat. Res. 428 (1999) 271-283. K. Umegaki, M. Fenech, Cytokinesis-block micronucleus assay in WIL2-NS cells: a sensitive system to detect chromosomal damage induced by reactive oxygen species
and activated human neutrophils, Mutagenesis $15(3)$
(2000) 261-269. P. Thomas, K. Umegaki, M. Fenech, Nucleoplasmic bridges are (2003) 187- 194. M. Fene Al, Chromosomal biomarkers of genomic instability relevant to cancer, Drug Discovery Today 22 (2002) 1128-1137. P. Tolbert, C. Shy, J. Allen, Micronuclei and other nuclear anomalies in buccal smears: a field test in snuff users, Am. J. Epidemiol. 8 (1991) 840 - 850. A. Suruda, P. Schulte, M. Boeniger, R. Hayes, G. Livingston, K. Steenland, P. Stewart, R. Herrick, D. Douthit, M. Fingerhut, Cytogenetic effects of

\section{Conclusions}

The mean of MN was slightly higher in women than in men but not statistically significant. In general, and in conformization with other studies, women appear to reach a threshold of genome instability faster then men. Results about age showed that the age category that show highest mean of MN was 3140. That result can be explained by the size of the sample of the last category that is approximately half of the others. 